\title{
Proteomics analysis of faecal proteins in the tick Haemaphysalis flava
}

\author{
Lei Liu, Yi-song Liu, Guo-Hua Liu and Tian-yin Cheng ${ }^{*}$
}

\begin{abstract}
Background: Ticks and tick-borne diseases are of major public health concern. Currently, development of vaccines against ticks is considered crucial for their control. A critical step in this process is the screening of viable antigens. Faeces are byproducts of digestion and blood meal utilization, and partly reflect the vitality and vector potential of ticks. However, an integrated analysis of proteins in tick faeces is lacking. The present study explored the protein components in the faeces of the tick Haemaphysalis flava, by liquid chromatography-tandem mass spectrometry (LC/MS-MS) to identify potential protein antigens for vaccine development against ticks.

Methods: Faeces from adult H. flava engorged females were collected. Proteins were extracted from faeces, and the trypsin-digested peptides were analyzed by LC/MS-MS. High confidence proteins were identified based on unique peptides revealed by MS. Potential faecal protein genes, as well as their sources, were also characterized by searching previous transcriptome datasets from the salivary glands and midgut of $\mathrm{H}$. flava.
\end{abstract}

Results: In total, 21 were recognized with confidence. Amongst these, 18 were of likely tick origin, while three proteins (serum albumin, haemoglobin $a$ and $\beta$ subunits) were likely from hosts. Seventeen unigenes corresponding to these proteins were retrieved by searching our previous H. flava salivary glands and midgut transcriptomic datasets. Some proteins were reported to prevent blood clotting, play a role in immunity and antibiosis, and formation of musculature. The functions of the remaining proteins are unknown.

Conclusions: Identifying antigens for tick vaccine development is feasible by analyzing the faecal proteome as well as the transcriptomes of salivary glands and midguts. The vast number of proteins detected in tick faeces highlights the complexity of blood digestion in ticks, a field that needs more investigation.

Keywords: Haemaphysalis flava, Tick, Faeces, Proteome, Blood digestion

\section{Background}

Ticks (Arthropoda: Arachnoidea) are pests of livestock, pets, wildlife and humans. Infestations result in lesions, emaciation, anaemia, paralysis, and possibly the death of hosts. More importantly, ticks are also reservoirs of pathogens and vectors of a myriad of viruses, bacteria, protozoa, fungi, and helminths $[1,2]$. Hence, controlling tick populations will have a significant impact on public health. The current strategy for tick control is to develop vaccines against them [3]. In this regard, screening for potential antigens is a critical step toward effective vaccine development.

\footnotetext{
* Correspondence: hn5368@163.com

College of Veterinary Medicine, Hunan Collaborative Innovation Center of Safety Production of Livestock and Poultry, Hunan Agricultural University, Changsha, Hunan Province 410128, People's Republic of China
}

Like other arthropods, the digestive tract of a tick consists of foregut, midgut and hindgut. While the hindgut mainly stores undigested wastes, the midgut is a major site for blood meal digestion. Malpighian tubules, which are the excretory organs in ticks, are connected to rectal caeca. Excreta from Malpighian tubules and digestion remnants converge in the hindgut and are discharged into the anal opening. Faeces are byproducts of digestion and blood meal utilization and are also associated with the vitality and vector potential of ticks [4]. Studies on the faecal components of ticks date back to the 1970s. In 1972, Hamdy compared faeces from 10 ticks and identified guanine and an unknown purine compound in these samples [5]. Later, proteins in the faeces of Hyalomma dromedarii were reported only during bloodfeeding [4]. In 1989, Katsuki et al. [6] discovered that 
albumins and haemoglobins accounted for $57 \%$ to $99 \%$ $(\mathrm{w} / \mathrm{w})$ of the proteins in the faeces of Haemaphysalis longicornis nymphs. Later, Frantisek et al. [7] reported the presence of xanthines and hypoxanthines in the excreta of some argasid tick species. In 2001, Stoyan [8] revealed that excreta of Ixodes ricinus contained uric acids and 8-azaguanine, and Daniel [9] detected ammonia in the faeces of Ixodes scapularis.

Thus far, integrated analyses of proteins in tick faeces have not been conducted. The present study explored faecal proteins in $H$. flava by liquid chromatography-tandem mass spectrometry (LC/MS-MS) for potential use as protein antigens for vaccine development against ticks.

\section{Methods}

Tick source and collection of faeces

The flagging method was used to collect ticks in Xinyang, Henan Province $\left(32^{\circ} 13^{\prime} \mathrm{N}, 114^{\circ} 08^{\prime} \mathrm{E}\right)$. More than 30 ticks in a non-engorged state were obtained and allowed to feed on hedgehogs in the laboratory. Ticks were harvested after detaching from hosts in a fullengorged state.

Adult female ticks were individually immobilized with their abdomen upwards onto a sterile glass slide using tapes. Each tick was subject to adequate stimuli developed in our laboratory and then kept in a wet box at $30-33^{\circ} \mathrm{C}$ for $3-4 \mathrm{~h}$. Faeces were collected from the anus and pooled into a clean $0.2 \mathrm{ml}$ centrifuge tube, and mixed with $100 \mu \mathrm{l}$ of lysis buffer (20 mM Tris- $\mathrm{HCl}, 0.2 \%$ SDS, pH 7.5) and incubated in a boiling water bath for 5 min. Ultrasonic pyrolysis was applied to the mixture for an additional $5 \mathrm{~min}$. Then, the lysates were centrifuged at $15,000 \times \mathrm{rpm}$ for $10 \mathrm{~min}$, and the supernatant was stored at $-80{ }^{\circ} \mathrm{C}$ until further use.

The conventional bicinchoninic acid (BCA) method was used to evaluate protein levels in the supernatant. An aliquot of the supernatant was subjected to protein analysis using SDS-PAGE.

\section{Protein preparation for high performance liquid chromatography (HPLC)}

An aliquot of the supernatant (50 $\mu$ g in weight) was mixed with 1,4-dithiothreitol (DTT) to a final concentration of $100 \mathrm{mM}$, and the mixture was boiled for $5 \mathrm{~min}$ and allowed to cool at room temperature. Then, a $200 \mu \mathrm{l}$ of UA buffer (150 mM Tris-HCl, $8 \mathrm{M}$ urea, $\mathrm{pH}$ 8.0) was added to the mixture, vortexed, transferred to an ultrafiltration tube with a $14 \mathrm{kDa}$ membrane, and centrifuged at $14,000 \times g$ for $15 \mathrm{~min}$. This process allowed proteins to be retained on the membrane, and the supernatant to be discharged. The step was repeated to ensure the complete removal of non-protein impurities. The proteins were then reconstituted in $200 \mu \mathrm{l}$ of $50 \mathrm{mM}$ iodoacetamide (IAA), shocked at $600 \times \mathrm{rpm}$ for $1 \mathrm{~min}$, and left for $30 \mathrm{~min}$ in the dark at room temperature. The remaining liquid was discarded by centrifuging at $14,000 \times g$ for $10 \mathrm{~min}$, and proteins retained on the membrane were washed twice with $200 \mu$ l of UA buffer, and further with $200 \mu \mathrm{l}$ of dissolution buffer $(25 \mathrm{mM}$ $\mathrm{NH}_{4} \mathrm{HCO}_{3}$ ). The protein extracts were digested with 40 $\mu \mathrm{l}$ of trypsin buffer ( $3 \mu \mathrm{g}$ trypsin from Promega in $40 \mu \mathrm{l}$ dissolution buffer) in a $37{ }^{\circ} \mathrm{C}$ water bath for $16-18 \mathrm{~h}$, and the resulting peptides were collected as a filtrate. The peptide concentration of the filtrate was measured at OD280 $\mathrm{nm}$.

\section{Faecal protein analysis by LC/MS-MS}

Peptides were separated using the Easy nLC HPLC system (Thermo Scientific, Waltham, MA, USA). Mobile phase A was $0.1 \%$ formic acid, and mobile phase B was $84 \%$ acetonitrile $(\mathrm{ACN})$ in $0.1 \%$ formic acid. Chromatographic columns were balanced with $95 \%$ mobile phase A before sample loading. Samples were injected onto a trap column $\left(2 \mathrm{~cm}^{*} 100 \mu \mathrm{m} 5 \mu \mathrm{m}-\mathrm{C} 18\right)$ by an autosampler, and then onto an analytical column $(75 \mu \mathrm{m} * 100 \mathrm{~mm} 3 \mu \mathrm{m}-\mathrm{C} 18)$. The flow rate was $300 \mathrm{nl} /$ min. Mobile phase B was invoked as an eluent.

Every sample after separation by HPLC was subjected to mass spectrometry analysis using a Q-Exactive ${ }^{\mathrm{TM}}$ mass spectrometer (Thermo Scientific). Nanospray ionization (NSI) was used as the ion source, and argon was used as collision gas. The whole analysis time was set at $240 \mathrm{~min}$.

\section{MS data analysis}

Raw data generated by MS/MS was imported into Bruker compass Data Analysis 4.0 (http://bruker-comp ass-dataanalysis.updatestar.com/). Then, unique peptides were searched in the peptide library conceptually translated from $H$. flava midgut and salivary gland transcriptome datasets (GSE67247, GSE69721, translated by TransDecoder with 25943 sequences in total) and Uniprot database by Mascot 2.0 (Matrix Science, Boston, USA). Carbamidomethylation of Cys was defined as a fixed modification, while oxidation of Met was defined as the variable modification. Searches had tryptic specificity and allowed a maximum of one missed cleavage and tolerance on the mass measurement of $20 \mathrm{ppm}$ in MS mode and $0.5 \mathrm{Da}$ for MS/MS ions. The significance threshold was set at $\geq 95 \%$, and only those proteins with $\geq 2$ unique significant peptides were selected.

\section{Protein identification and database search}

Proteins were identified using the peptide library conceptually translated from the $H$. flava midgut and salivary gland transcriptome datasets (https://www.ncbi.nlm.nih.g ov/gds/?term=GSE67247; https://www.ncbi.nlm.nih.gov/ gds/?term=GSE69721), NCBInr (https://www.ncbi.nlm.ni 
h.gov/protein) and UniProt (http://www.uniprot.org/blast/) databases. UniGenes were also retrieved by searching datasets GSE67247 (https://www.ncbi.nlm.nih.gov/gds/?term=G SE67247) and GSE69721 (https://www.ncbi.nlm.nih.gov/ gds/?term=GSE69721), previously deposited in NCBI by our group.

\section{Results}

\section{Collection of $H$. flava faeces}

We have developed a feasible method collect tick faeces in the laboratory. Using this method, we collected two batches of faeces from female ticks. Analysis of faecal proteins by HPLC and SDS-PAGE showed the presence of a complex set of proteins in the faecal extracts of $H$. flava, with molecular weights ranging from $15 \mathrm{kDa}$ to $170 \mathrm{kDa}$ (Fig. 1). Robust bands were observed at $13 \mathrm{kDa}$, $70 \mathrm{kDa}, 100 \mathrm{kDa}$ and $170 \mathrm{kDa}$ (Fig. 1).

The protein concentration of faecal extracts was estimated to be $1.39 \mathrm{mg} / \mathrm{ml}$ by the BCA method.

\section{Faecal protein analysis by LC/MS-MS}

Overall, we analyzed two batches of faecal proteins by LC/MS-MS and obtained 80 high confidence peptides $(\geq$ 95\%) in total. Twenty-one proteins were identified by searching the peptide library conceptually translated from $H$. flava midgut and salivary gland transcriptome datasets, NCBInr and UniProt databases (Table 1). Amongst these, 18 proteins were annotated as tick proteins. However, one protein, serum albumin (A0A140T897), was likely a host protein. The remaining two high confidence proteins, haemoglobin $\alpha$ and $\beta$ subunits, were likely from hedgehogs, the host used in the present study.

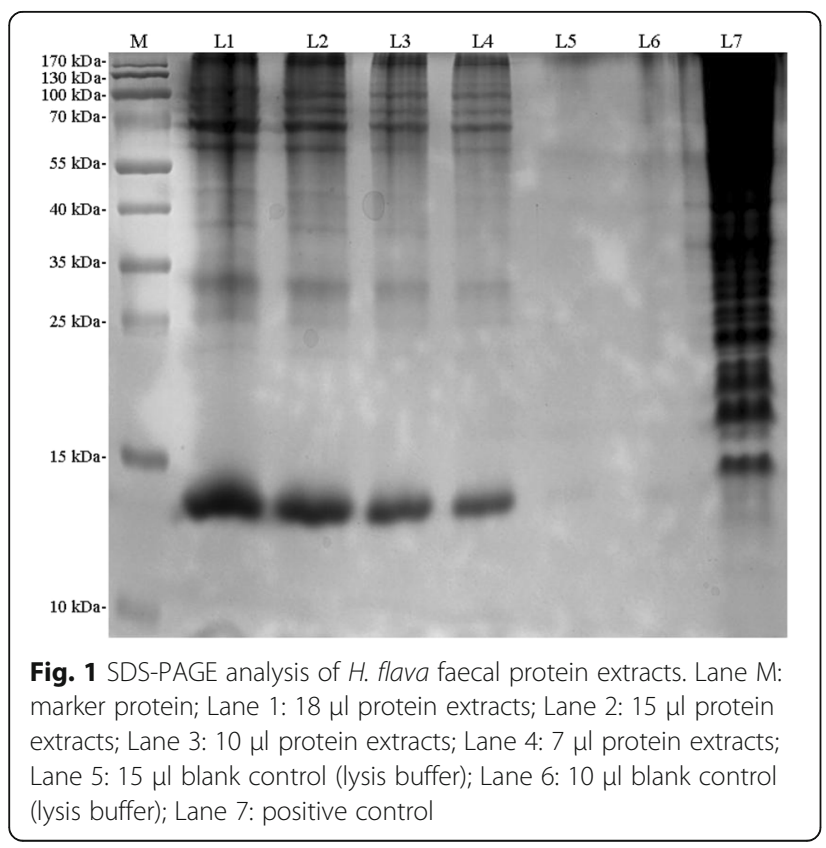

Based on protein annotations, we searched the $H$. flava salivary gland (GSE67247) and midgut (GSE69721) transcriptomic libraries and selected 17 unigenes encoding these proteins (Table 2). Following alignment of proteins with other tick species, 13 unigenes were found to be homologs of actin, enolase, mucin, AV422, elongation factor 2, cysteine-rich protein, histone $\mathrm{H} 2 \mathrm{~B}$, serpin, paramyosin and microplusin-1. However, Contig13170, Contig4707, Contig15192 and Contig-499 were found to encode a fraction of hypertrophic, $\alpha$-2-macroglobulin, chitinase and cystatin, respectively. The identities between the $H$. flava proteins and their tick homologues were highly variable, and ranged from $41 \%$ to $100 \%$. Notably, H. flava enolase had an $84 \%$ amino acid (aa) identity to the I. ricinus homologue, and an $82.4 \%$ aa identity to the Ornithodoros moubata homologue; AV422 in H. flava showed 95.2\% identity with the Amblyomma americanum homologue; H. flava histone H2B had $98.4 \%$ of identity with the $I$. scapularis homologue; the identity of $H$. flava paramyosin was $98.1 \%, 97 \%$ and $94 \%$ compared with the H. longicornis, Rhipicephalus microplus and I. scapularis homologues, respectively; homology of the elongation factor-2 in H. flava was 98.3\%, 97.7\%, 97.7\%, 97.7\%, 96.3\% and $90.5 \%$ compared with Rhipicephalus appendiculatus, Amblyomma parvum, Amblyomma cajennense, Amblyomma aureolatum, Hyalomma excavatum and $I$. ricinus, respectively. However, unigenes corresponding to ixolaris, neutrophil elastase inhibitor, serotonin and histamine binding protein were not identified.

\section{Discussion}

We have identified 21 proteins in the faeces of the tick, $H$. flava. Amongst these, 18 were confirmed to be of tick origin based on the retrieval of their protein homologs by searching databases of $H$. flava salivary gland and midgut transcriptomes. To our knowledge, this is the first faecal proteomic study in ticks.

The life-cycle of hard ticks includes four developmental stages, i.e. eggs, larvae, nymphs and adults. Except for eggs, ticks of the last three stages require blood-feeding for their survival. It is likely that serum albumins may have originated from hosts of $H$. flava nymphs because these do not digest serum albumins completely, as reported for $H$. longicornis nymphs [6]. Haemoglobin $\alpha$ and $\beta$ subunits from hedgehogs were also detected in the faeces of $H$. flava. This observation was consistent with other reports of haemoglobin in ticks faeces based on spectrophotometry $[4,6]$. Furthermore, our search for homologs of ixolaris, a neutrophil elastase inhibitor, serotonin and histamine binding proteins and an uncharacterized protein did not yield any positive result. The functions of five proteins, namely cysteine-rich protein, mucin, elongation factor-2, hypertrophic and 
Table 1 Proteins with high confidence in H. flava faecal protein extracts detected by LC/MS-MS

\begin{tabular}{|c|c|c|c|}
\hline No. & Unique peptides & Peptides deduced from & $\begin{array}{l}\text { Coverage } \\
(\%)\end{array}$ \\
\hline 1 & $\begin{array}{l}\text { AGFAGDDAPR; CDVDIR; DSYVGDEAQSK; IIAPPER; LCYVALDFEQEMATAASSSSLEK; } \\
\text { QEYDESGPSIVHR; VAPEEHPVLLTEAPLNPK }\end{array}$ & cds.Contig217 in GSE67247 & 23.2 \\
\hline \multirow[t]{2}{*}{2} & \multirow{2}{*}{$\begin{array}{l}\text { AAEQSLEESQARVNELTTINVNIAAAKNK; EKSDLTVQLMQLSDR; RQLNEQEGLSQQNLTR; } \\
\text { YQAQITELEMSLDAANKQNMDLQK }\end{array}$} & cds.Contig2051 in GSE69721 & 9.6 \\
\hline & & cds.Contig27282 in GSE67247 & 9.6 \\
\hline 3 & CLTDIQAGLEK; ELIGFVAEGSQELFK; HAPCLGQTLPDQK; HAPCLGQTLPDQKK & cds.Contig2959 in GSE67247 & 17.2 \\
\hline 4 & DANECLPQEVAGCD; VADPDDCGK; VNCPPLQHFSK; YSLCTATFSTK & cds.Contig6112 in GSE67247 & 36.3 \\
\hline 5 & IQIVGDDLTVTNPK; LAVQEFMILPTGATTFTEAMK; YMGKSVFKAVDNINK & cds.Contig2263 in GSE67247 & 11.3 \\
\hline 6 & YVPDPDDCTK; YTVCSGGFGMK & cds.Contig13170 in GSE67247 & 38.9 \\
\hline 7 & VEGLENYDTVLELTK; VETQWAGLNYR & cds.Contig499 in GSE69721 & 24.8 \\
\hline 8 & EIQTAVR; LLLPGELAK & cds.Contig27398 in GSE67247 & 11.0 \\
\hline \multirow[t]{2}{*}{9} & \multirow[t]{2}{*}{ CPCYGTDR; GCASATSVLTR } & cds.Contig6678 in GSE69721 & 24.4 \\
\hline & & cds.Contig27530 in GSE67247 & 11.4 \\
\hline 11 & VDKLMGR; VTDGALWVDCVSGVCVQTETVLR & cds.Contig198 in GSE69721 & 3.7 \\
\hline 10 & DQAGEFNTR; TDDLCAVQK & cds.Contig3975 in GSE69721 & 8.9 \\
\hline \multirow[t]{2}{*}{12} & \multirow[t]{2}{*}{ SVDFANEGPR; YNLVPAMR } & cds.Contig7475 in GSE67247 & 10.3 \\
\hline & & cds.Contig36225 in GSE69721 & 15.1 \\
\hline 13 & SVGSFEFQSTLPADASPK; FTEAEITTEQTDR & cds.Contig4707 in GSE67247 & 6.6 \\
\hline 14 & AAPEVGDGAAK; LDNGVIAPFDPYLDLK & cds.Contig15192 in GSE69721 & 21.1 \\
\hline 15 & $\begin{array}{l}\text { ALVTGLWGK; DFTPAAQAAFQK; FFDSFGDLSSADAVMGNPK; VKVEEFGGEALGR; } \\
\text { VLQSMGDGIK; VHLTAEEK; LSELHCDK; LHVDPENFR; NLDNLK }\end{array}$ & $\begin{array}{l}\text { P02059 in UniProt; } \\
\text { Hemoglobin subunit } \beta ; \text { Erinaceus europaeus }\end{array}$ & 67.4 \\
\hline 16 & LGGHGGEYGGEALDR; LRVDPVNFK; MFQAHPTTK; VDPVNFK; FQAHPTTK & $\begin{array}{l}\text { P01949 in UniProt; } \\
\text { Hemoglobin subunit a; E. europaeus }\end{array}$ & 23.4 \\
\hline 17 & $\begin{array}{l}\text { AEFVEVTK; GACLLPK; HLVDEPQNLIK; KVPQVSTPTLVEVSR; LVTDLTK; LWSTQTALA; } \\
\text { QNCDQFEK; QTALVELLK; YICDNQDTISSK }\end{array}$ & $\begin{array}{l}\text { A0A140T897 in UniProt; } \\
\text { Serum albumin; Bos taurus }\end{array}$ & 18.5 \\
\hline 18 & ICELSSDTHQEHANTFLPDDVK; LNCEDLDCVFTK; QRLNCEDLDCVFTK & $\begin{array}{l}\text { A1Y1T6 in UniProt; } \\
\text { Neutrophil elastase inhibitor; Rhipicephalus } \\
\text { microplus }\end{array}$ & 27.7 \\
\hline 19 & CPEATNYGFLIFAR; FEAEDNGTPCQTK & $\begin{array}{l}\text { G3MTW3 in UniProt; } \\
\text { Uncharacterized protein; Amblyomma } \\
\text { maculatum }\end{array}$ & 17.7 \\
\hline 20 & HVPDYCTFVFNVFCAK; HVPDYCTFVFNVFCAKDR & $\begin{array}{l}\text { Q8WSK7 in UniProt; } \\
\text { Serotonin and histamine binding protein; } \\
\text { Dermacentor reticulatus }\end{array}$ & 16.8 \\
\hline 21 & ANIPRWYYDTNNATCEMFTYGGITGNKNNFESEEECK; CNESCNDAPKPPCSLEVDYGVGR & $\begin{array}{l}\text { Q964Q0 in UniProt; } \\
\text { Ixolaris; Ixodes scapularis }\end{array}$ & 36.4 \\
\hline
\end{tabular}

microplusin-1, are unknown. The remaining 11 proteins may function in prevention of blood clotting, immunemediation and antibiosis, and formation of musculature in ticks.

Enolase, AV422, serpin-2 and cystatin-2 are proteins that hinder blood clotting, but their underlying mechanisms of action vary. $\mathrm{Xu}$ et al. [10] revealed the fulllength enolase gene to be 1988 bp with an open reading frame (ORF) containing 1302 bp that encodes a protein with 433 aa. Recombinant enolase could bind human plasminogen, a key clotting factor, which could be activated during coagulation in a dose-dependent manner. An enolase from Ornithodoros moubata is secreted into the saliva, where it functions as the receptor of plasminogen to stimulate fibrinolysis in hosts, in order to maintain the fluidity of the blood during feeding [11]. Further, RNAi and immunization studies have demonstrated that inactivating enolase could affect tick reproduction, indicating that this could be a new strategy for tick control [11].

The full-length AV422 gene in H. flava was 1152 bp, encoding a protein with 231 aa (unpublished data). Recombinant AV222 could significantly extend the prothrombin time (PT), thrombin time (TT) and activated partial thromboplastin time (APTT) in vitro (unpublished data). AV422 in Amblyomma americanum has been reported to mediate anti-haemostasis and anticomplement processes during feeding by postponing the 
Table 2 Unigenes from transcriptome datasets homologous to the proteins identified by faecal proteomic analysis

\begin{tabular}{|c|c|c|c|c|c|c|c|}
\hline \multirow[t]{2}{*}{ No. } & \multicolumn{2}{|l|}{ Unigene } & \multicolumn{5}{|l|}{ Putative protein } \\
\hline & ID & $\begin{array}{l}\text { Nucleotide } \\
\text { length (bp) }\end{array}$ & Protein length (aa) & Protein annotation & E-value & Score & Identity (\%) \\
\hline 1 & Contig217 in GSE67247 & 1521 & 376 & Q6X4V4, actin, R. microplus & 0.0 & 1967 & 100.0 \\
\hline \multirow[t]{2}{*}{2} & Contig2051 in GSE69721 & 3161 & 877 & \multirow[t]{2}{*}{ J7LVN2, paramyosin, H. longicornis } & \multirow[t]{2}{*}{0.0} & \multirow[t]{2}{*}{4180} & \multirow[t]{2}{*}{98.1} \\
\hline & Contig27282 in GSE67247 & 3907 & 877 & & & & \\
\hline 3 & Contig2959 in GSE67247 & 1211 & 231 & M4PPE7, AV422, A. americanum & $9.3 e-164$ & 1186 & 95.2 \\
\hline 4 & Contig2263 in GSE67247 & 2372 & 433 & D4P967, enolase, Ornithodoros moubata & 0.0 & 1878 & 82.4 \\
\hline 5 & Contig6112 in GSE67247 & 444 & 124 & Q2PGH6, mucin, H. longicornis & $1.2 \mathrm{e}-59$ & 487 & 74.5 \\
\hline 6 & Contig13170 in GSE67247 & 787 & 230 & A0A023G8D0, pertrophin, A. triste & $7.9 e-36$ & 301 & 90.7 \\
\hline 7 & Contig499 in GSE69721 & 467 & 109 & A0A023G8F8, cystatin-2, A. triste & $8.8 e-35$ & 310 & 80.3 \\
\hline 8 & Contig27398 in GSE67247 & 784 & 125 & A0A131Y6E4, histone $\mathrm{H}_{2} \mathrm{~B}$, I. scapularis & $1.2 \mathrm{e}-79$ & 614 & 98.4 \\
\hline \multirow[t]{2}{*}{9} & Contig6678 in GSE69721 & 398 & 78 & \multirow{2}{*}{$\begin{array}{l}\text { A0A034WXB2, cysteine-rich protein, } \\
\text { R. microplus }\end{array}$} & $4.4 \mathrm{e}-22$ & 224 & 65.8 \\
\hline & Contig27530 in GSE67247 & 751 & 167 & & $3.3 e-31$ & 301 & 54.1 \\
\hline 10 & Contig198 in GSE69721 & 2899 & 847 & $\begin{array}{l}\text { A0A } 1312556 \text {, elongation factor } 2 \text {, } \\
\text { R. appendiculatus }\end{array}$ & 0.0 & 4329 & 98.3 \\
\hline 11 & Contig3975 in GSE69721 & 1669 & 202 & A0A023FTF7, microplusin-1, A. maculatum & $2.3 e-71$ & 567 & 72.8 \\
\hline \multirow[t]{2}{*}{12} & Contig7475 in GSE67247 & 937 & 174 & \multirow[t]{2}{*}{ Q75Q63, serpin-2, H. longicornis } & $3 e-108$ & 295 & 90.0 \\
\hline & Contig36225 in GSE69721 & 359 & 119 & & $1 e-61$ & 202 & 90.0 \\
\hline 13 & Contig4707 in SE67247 & 1665 & 551 & A0A023FLU0, a-macroglobulin, A. cajennense & 0.0 & 2323 & 80.4 \\
\hline 14 & Contig15192 in SE69721 & 494 & 128 & A0A02323FPH1, chitinase, A. cajennense & $9.7 e-54$ & 468 & 73.8 \\
\hline
\end{tabular}

plasma clotting time, preventing platelet aggregation, and reducing the final complement complexes [12]. It was suggested that AV222 could be a potential candidate antigen for vaccine development against ticks, consistent with our observation.

The full-length serpin-2 gene in $H$. flava was $1467 \mathrm{bp}$, encoding a protein of 398 aa with a signal peptide of 17 aa (unpublished data). The protein structure and function of $H$. flava sepin-2 was similar to serpin-2 in $H$. longicornis, but not to serpin-1 [13]. They shared $87 \%$ aa identity, and both could significantly delay APTT.

Moreover, Contig499 identified in the transcriptomic library of midguts encoded a protein with $78 \%$ aa identity with Hlcyst-3, a member of cystatins family. Over the last two decades, several cystatins from different tick species have been identified, and their biochemical functions have been analyzed concerning the physiology and blood-feeding lifestyle of ticks. Zhou et al. [14] confirmed that recombinant Hlcyst-3 could inhibit papain and cathepsin $\mathrm{L}$ and that its expression was highest in tick midguts.

The full-length sequence of histone H2B was 124 aa based on two unigenes, Contig27398 and Contig1248. It could react with rickettsial adhesin $\mathrm{OmpB}$, thus indicating a role in mediating Rickettsia felis internalization into ISE6 cells [15].

The protein encoded by Contig4707 was found to share $80.4 \%$ and $71 \%$ aa identity to a fragment of a2-macroglobulin in A. cajennense and I. scapularis, respectively. However, the identity between the aa sequence predicted from Contig4707 and $\alpha 2$-macroglobulin precursor splice variant 1 in O. moubata was only $29 \%$. $\alpha 2$ macroglobulin in O. moubata was isolated and characterized from plasma [16], and later the $\alpha 2$-macroglobulin gene was cloned in the same soft tick species [17]. $\alpha 2$ macroglobulin was shown to be expressed in all life stages of the hard tick $I$. ricinus with the highest expression in haemolymphs, salivary glands and ovarioles, but not in midguts [18]. Further RNAi studies indicated that challenged ticks had compromised ability to phagocytize Chryseobacterium indologenes but not Borrelia burgdorferi and Staphylococcus xylosus [18].

Paramyosin was initially isolated from large filaments of unstriated muscles of molluscs [19] and was suggested to play a critical role in determining the length and stability of muscle filaments in nematodes [20]. The full-length of paramyosin was 872 aa based on two unigenes, Contig2051 and Contig27282. The protein was expressed in all tissues and all developmental stages of $R$. microplus but was not found in the saliva [21]. As a component of tick myofibrils, it was also shown to have antibiotic activity. Recombinant paramyosin was able to bind IgG and collagen [21]. Further studies revealed that $R$. microplus paramyosin could induce an immune response during tick infestations. $R$. microplus paramyosin also showed a high transcription rate in organs which 
did not have a highly-developed musculature like fat bodies. These observations suggested the presence of additional, non-muscle related functions during tickbovine interactions [22].

Actin is a major component of muscles in animals and exists in almost all muscle and non-muscle cell structures of eukaryotes. The aa sequences of actin are highly conserved between species. The homology of its genes between human and Drosophila is more than 93\% [23]. In ticks, $H$. flava shares a $100 \%$ homology with $R$. microplus and $99 \%$ with O. moubata [24].

The full-length microplusin was estimated to be 159 aa. We compared the microplusin sequences of $H$. flava with Amblyomma maculatum, Amblyomma triste and A. cajennense, and the homology was found to be $74 \%$, $73 \%$ and $71 \%$, respectively. The homology between $H$. flava and $R$. microplus microplusin was only $29 \%$. The full-length elongation factor-2 in $\mathrm{H}$. flava was estimated to be 842 aa, and that of mucin was 117 aa. Mucin of $H$. flava shared $81 \%$ homology with that of $H$. longicornis. The estimated full-length of a cysteine-rich protein was 117 aa and shared a homology of $42 \%$ with that of $I$. scapularis. The biological functions of the four proteins are unknown, and further studies are needed to understand their roles.

Chitinase hydrolyses are the $\beta-1,4$ glycosidic linkages of $\mathrm{N}$-acetylglucosamines. Contig15192 encoded putative chitinase in $H$. flava and has a full-length ORF of 494 bp encoding a peptide with 128 aa. Its aa identity with that in $A$. cajennense was $73.8 \%$. Immunization of rabbits with recombinant chitinase reduced feeding efficiency and prevented moulting in $H$. longicornis $[25,26]$. A recent study revealed that silencing chitinase in A. americanum harmed the tick cement cone stability [27], indicating that chitinase could be used as a novel acaricide. It is notable that the chitinase identified in the present study had low aa identity with that in $H$. longicornis and $A$. americanum, suggesting that it could be a different protein. Thus, the function of chitinase in $H$. flava needs further clarification.

\section{Conclusions}

In total, 21 proteins were identified in the faecal proteome of $H$. flava females with high confidence. Together with previous $H$. flava salivary gland and midgut transcriptomes, it was demonstrated that 18 proteins were from ticks as their corresponding genes could be found in those datasets. Thus, the proteomics informed by transcriptomics (PIT) in the present study is a feasible tool to identify proteins. This tool will further facilitate studies on the biology of blood meal digestion and provide clues for the control of tick infestations.
Moreover, the present study also highlights the complexity of faecal protein components, which mirrors the complexity of the process of blood digestion in ticks. More investigations are needed to elucidate the roles of these proteins in blood meal processing, interactions between ticks and hosts, and interventions in tick-borne pathogen transmission.

\section{Abbreviations \\ aa: Amino acids; ACN: Acetonitrile; APTT: Activated partial thromboplastin time; BCA: Bicinchoninic acid; DTT: 1,4-dithiothreitol; HPLC: High performance liquid chromatography; IAA: lodoacetamide; LC/MS-MS: Liquid chromatography-tandem mass spectrometry; NCBInr: National center for biotechnology information non-redundant; NSI: Nanospray ionization; PIT: Proteomics informed by transcriptomics; PT: Prothrombin time; RACE: Rapid-amplification of CDNA ends; SDS-PAGE: Sodium dodecyl sulfate polyacrylamide gel electrophoresis; TT: Thrombin time}

\section{Acknowledgements}

Not applicable.

\section{Funding}

This research was funded by a grant from the National Natural Science Foundation of China (No. 31372431) and a talented faculty foundation of Hunan Agricultural University (No. 15YJ05).

\section{Availability of data and materials}

The proteomic data generated and analyzed during the current study are available in the iProX repository, http://iprox.org/page/ SSV024.html;url=1517022379184p9zy, with the key gb7P. The H. flava midgut and salivary gland transcriptome datasets are available in the NCBI repository, GSE67247 (https://www.ncbi.nlm.nih.gov/gds/?term=GSE67247) and GSE69721 (https://www.ncbi.nlm.nih.gov/gds/?term=GSE69721).

\section{Authors' contributions}

TYC designed the experiments. LL collected the tick faeces and prepared the protein extracts for HPLC/MS-MS. TYC, LL, YSL and GHL analyzed the data. LL, TYC, YSL and GHL collaborated in writing and editing the manuscript. All authors read and approved the final version of the manuscript

\section{Ethics approval and consent to participate}

All procedures involving animals in the present study were approved and overseen by the Hunan Agricultural University Institutional Animal Care and Use Committee (No. 43321503).

Consent for publication

Not applicable.

\section{Competing interests}

The authors declare that they have no competing interests.

\section{Publisher's Note}

Springer Nature remains neutral with regard to jurisdictional claims in published maps and institutional affiliations.

Received: 10 August 2017 Accepted: 24 January 2018

Published online: 08 February 2018

References

1. de la Fuente J, Antunes S, Bonnet S, Cabezas-Cruz A, Domingos AG, EstradaPeña A, et al. Tick-pathogen interactions and vector competence: Identification of molecular drivers for tick-borne diseases. Front Cell Infect Microbiol. 2017;7:114.

2. Yu Z, Wang $H$, Wang $T$, Sun W, Yang $X$, Liu J. Tick-borne pathogens and the vector potential of ticks in China. Parasit Vectors. 2015:8:24

3. de la Fuente J, Moreno-Cid JA, Galindo RC, Almazan C, Kocan KM, Merino O, et al. Subolesin/Akirin vaccines for the control of arthropod vectors and vectorborne pathogens. Transbound Emerg Dis. 2013;60(s2):172-8. 
4. Hamdy BH. Biochemical and physiological studies of certain ticks (Ixodoidea). Cycle of nitrogenous excretion in Argas (Persicargas) arboreus Kaiser, Hoogstraal \& Kohls (Argasidae). J Med Entomol. 1973;10(1):53-7.

5. Hamdy BH. Biochemical and physiological studies of certain ticks (Ixodoidea). Nitrogenous excretory products of Argas (Persicargas) arboreus Kaiser, Hoogstraal \& Kohls, and of other argasid and ixodid species. J Med Entomol. 1972;9(4):346-50.

6. Koh K, Shiraishi S, Uchida TA. Accumulation, digestion and excretion of bloodmeal protein during feeding in nymphal Haemaphysalis longicornis. J Fac Agr Kyushu U. 1989;34:107-14.

7. Dusbábek F, Simek P, Jegorov A, Tríska J. Identification of xanthine and hypoxanthine as components of assembly pheromone in excreta of argasid ticks. Exp Appl Acarol. 1991;11(4):307-16.

8. Grenacher S, Kröber T, Guerin PM, Vlimant M. Behavioural and chemoreceptor cell responses of the tick, Ixodes ricinus, to its own faeces and faecal constituents. Exp Appl Acarol. 2001;25(8):641-60.

9. Sonenshine DE, Adams T, Allan SA, Mclaughlin J, Webster FX. Chemical composition of some components of the arrestment pheromone of the black-legged tick, Ixodes scapularis (Acari: Ixodidae) and their use in tick control. J Med Entomol. 2003;40(6):849-59.

10. $\mathrm{Xu} \mathrm{XL}$, Cheng TY, Yang $\mathrm{H}$. Enolase, a plasminogen receptor isolated from salivary gland transcriptome of the ixodid tick Haemaphysalis flava. Parasitol Res. 2016;115(5):1955-64.

11. Díaz-Martín V, Manzano-Román R, Oleaga A, Encinas-Grandes A, PérezSánchez R. Cloning and characterization of a plasminogen-binding enolase from the saliva of the argasid tick Ornithodoros moubata. Vet Parasitol. 2013; 191(3-4):301-14.

12. Mulenga A, Kim TK, Ibelli AM. Deorphanization and target validation of cross-tick species conserved novel Amblyomma americanum tick saliva protein. Int J Parasitol. 2013;43(6):439-51.

13. Imamura S, da Silva Vaz J, Sugino M, Ohashi K, Onuma MA. serine protease inhibitor (serpin) from Haemaphysalis longicornis as an anti-tick vaccine. Vaccine. 2005;23(10):1301-11.

14. Zhou JL, Liao M, Gong HY, Xuan XN, Fujisaki K. Characterization of Hlcyst-3 as a member of cystatins from the tick Haemaphysalis longicornis. Exp Appl Acarol. 2010;51(4):327-33.

15. Thepparit C, Bourchookarn A, Petchampai N, Barker SA, Macaluso KR. Interaction of Rickettsia felis with histone $\mathrm{H} 2 \mathrm{~B}$ facilitates the infection of a tick cell line. Microbiology. 2010;156(9):2855-63.

16. Kopácek P, Weise C, Saravanan T, Vítová K, Grubhoffer L. Characterization of an alpha-macroglobulin-like glycoprotein isolated from the plasma of the soft tick Ornithodoros moubata. Eur J Biochem. 2000;267(2):465-75.

17. Saravanan T, Weise C, Sojka D, Kopácek P. Molecular cloning, structure and bait region splice variants of alpha2-macroglobulin from the soft tick Ornithodoros moubata. Insect Biochem Mol Biol. 2003;33(8):841-51.

18. Buresova V, Hajdusek O, Franta Z, Sojka D, Kopacek P. IrAM-An alpha2 macroglobulin from the hard tick Ixodes ricinus: characterization and function in phagocytosis of a potential pathogen Chryseobacterium indologenes. Dev Comp Immunol. 2009;33(4):489-98.

19. Castellani L, Vibert P, Cohen C. Structure of myosin/paramyosin filaments from a molluscan smooth muscle. J Mol Biol. 1983;167(4):853-72.

20. Mackenzie JM, Epstein HF. Paramyosin is necessary for determination of nematode thick filament in vivo. Cell. 1980;22(3):747-55.

21. Ferreira CA, Barbosa MC, Silveira TC, Valenzuela JG, Vas Ida S Jr, Masuda A cDNA cloning, expression and characterization of a Boophilus microplus paramyosin. Parasitology. 2002;125(3):265-74.

22. Leal BF, Seixas A, Mattos RT, Coutinho ML, Masuda A, da Silva Vaz I Jr et al. Tissue expression and the host's immunological recognition of a Rhipicephalus microplus paramyosin. Vet Parasitol. 2013;197(1-2):304-11.

23. da Silva Vaz I Jr, Imamura S, Nakajima C, de Cardoso FC, Ferreira CA, Renard $\mathrm{G}$, et al. Molecular cloning and sequence analysis of CDNAs encoding for Boophilus microplus, Haemaphysalis longicornis and Rhipicephalus appendiculatus actins. Vet Parasitol. 2005;127(2):147-55.

24. Horigane M, Ogihara K, Nakajima Y, Honda H, Taylor D. Identification and expression analysis of an actin gene from the soft tick, Ornithodoros moubata (Acari: Argasidae). Arch Insect Biochem Physiol. 2010;64(4):186-99.

25. You M, Xuan X, Tsuji N, Kamio T, Taylor D, Suzuki N, et al. Identification and molecular characterization of a chitinase from the hard tick Haemaphysalis longicornis. J Biol Chem. 2003;278(10):8556-8563.
26. Assenga SP, You M, Shy CH, Yamagishi J, Sakaguchi T, Zhou J, et al. The use of a recombinant baculovirus expressing a chitinase from the hard tick Haemaphysalis longicornis and its potential application as a bioacaricide for tick control. Parasitol Res. 2006:98(2):111-8.

27. Kim TK, Curran J, Mulenga A. Dual silencing of long and short Amblyomma americanum acidic chitinase forms weakens the tick cement cone stability. J Exp Biol. 2014;217(19):3493-503.

\section{Submit your next manuscript to BioMed Central and we will help you at every step:}

- We accept pre-submission inquiries

- Our selector tool helps you to find the most relevant journal

- We provide round the clock customer support

- Convenient online submission

- Thorough peer review

- Inclusion in PubMed and all major indexing services

- Maximum visibility for your research

Submit your manuscript at www.biomedcentral.com/submit

) Biomed Central 